\title{
Reduced Kidney Function and Preclinical Atherosclerosis in HIV-Infected Individuals: The Study of Fat Redistribution and Metabolic Change in HIV Infection (FRAM)
}

\author{
Vasantha Jotwani ${ }^{a, b}$ Rebecca Scherzer ${ }^{a, b} \quad$ Andy Choi ${ }^{a, b}$ Lynda Szczech $^{c}$ \\ Joseph F. Polak ${ }^{d}$ Richard A. Kronmal ${ }^{\mathrm{e}}$ Carl Grunfeld ${ }^{\mathrm{a}, \mathrm{b}}$ Michael Shlipak ${ }^{\mathrm{a}, \mathrm{b}}$

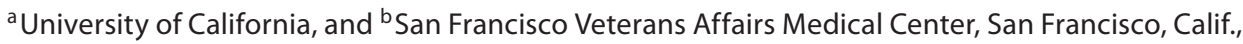 \\ 'Duke University Medical Center, Durham, N.C., ${ }^{\mathrm{d}}$ Tufts Medical Center, Boston, Mass., and 'University of Washington, \\ Seattle, Wash., USA
}

\section{Key Words}

Cystatin C • Intima-medial thickness · HIV • Atherosclerosis •

Cardiovascular disease $\cdot$ Kidney

\begin{abstract}
Background/Aims: Reduced kidney function and albuminuria are associated with higher risk for cardiovascular disease (CVD) and mortality in HIV-infected individuals. We investigated whether reduced estimated glomerular filtration rate (eGFR) and albuminuria are associated with subclinical vascular disease, as assessed by carotid intima-medial thickness (cIMT). Methods: Cross-sectional analysis of 476 HIV-infected individuals without clinical evidence of CVD enrolled in the Fat Redistribution and Metabolic Change in HIV infection (FRAM) study, using multivariable linear regression. eGFR Cys $_{\text {s }}$ and eGFR $R_{C r}$ were calculated from cystatin $C$ and creatinine levels. Albuminuria was defined as a positive urine dipstick $(\geq 1+)$ or urine albumin-to-creatinine ratio $\geq 30 \mathrm{mg} / \mathrm{g}$. Common and internal cIMT were measured by high-resolution B-mode ultrasound. Results: In unadjusted analyses, eGFR $_{\text {cys }}$ and eGFR $\mathrm{Cr}_{\mathrm{r}}$ were strongly associated with common and internal cIMT. Each $10 \mathrm{ml} / \mathrm{min} / 1.73 \mathrm{~m}^{2}$ decrease in eGFR $_{\text {cys }}$ and eGFR $\mathrm{R}_{\mathrm{cr}}$ was associated with a $0.008 \mathrm{~mm}$ higher
\end{abstract}

\section{KARGER}

Fax +41613061234 E-Mail karger@karger.ch www.karger.com
() 2011 S. Karger AG, Basel

Accessible online at:

www.karger.com/ajn common cIMT ( $p=0.003, p=0.01)$ and 0.024 and $0.029 \mathrm{~mm}$ higher internal cIMT ( $p=0.003)$, respectively. These associations were eliminated after adjustment for age, gender, and race. Albuminuria showed little association with common or internal CIMT in all models. Conclusions: In HIV-infected individuals without prior CVD, reduced kidney function and albuminuria were not independently associated with subclinical vascular disease, as assessed by cIMT. These results suggest that research should focus on searching for novel mechanisms by which kidney disease confers cardiovascular risk in HIV-infected individuals. Copyright $\odot 2011$ S. Karger AG, Basel

\section{Introduction}

Cardiovascular disease (CVD) is an important cause of morbidity and mortality in HIV-infected patients. Previous studies have demonstrated that HIV-infected patients have a higher prevalence and incidence of CVD when compared with age-matched uninfected controls

Andy Choi is deceased.
Michael G. Shlipak, MD, MPH

San Francisco Veterans Affairs Medical Center

4150 Clement Street, Box 111A1

San Francisco, CA 94121 (USA)

Tel. +1 415750 2093, E-Mail michael.shlipak@ucsf.edu 
[1]. Carotid intima-medial thickness (cIMT) is an established measure of subclinical vascular disease that is strongly associated with future CVD events in the general population [2]. In the study of Fat Redistribution and Metabolic Change in HIV Infection (FRAM), HIV-infected patients without clinical CVD had substantially higher cIMT compared with uninfected individuals, even after adjustment for traditional CVD risk factors [3]. This finding suggests that HIV infection may promote the development of atherosclerosis or vessel hypertrophy, though its mechanisms remain unclear.

A potential contributor to vascular disease in the setting of HIV infection is kidney disease. Early in the HIV epidemic, HIV-associated nephropathy (HIVAN) was an important cause of HIV-related kidney disease [4]. Although the prevalence of clinically significant cases of HIVAN has decreased considerably with the advent of antiretroviral therapy [5], HIV infection remains associated with a higher prevalence of microalbuminuria [6] and risk for end-stage renal disease (ESRD) [7]. For instance, in the first FRAM examination, HIV-infected individuals had higher levels of microalbuminuria and significantly worse renal function, as measured by cystatin C, compared to uninfected controls $[6,8]$. Furthermore, cystatin C-based estimated glomerular filtration rate $\left(\mathrm{eGFR}_{\mathrm{Cys}}\right)$ and albuminuria were strong and independent risk factors for mortality among individuals with HIV [9]. In the general population, both chronic kidney disease (CKD) and albuminuria are well established and independent risk factors for cardiovascular events, including myocardial infarction, heart failure, stroke and cardiovascular mortality [10]. A recent study from the Veterans Administration's National HIV Registry found that CKD and albuminuria are independently associated with CVD and mortality in HIV-infected individuals as well [11].

Despite these strong associations, the mechanisms by which CKD may contribute to cardiovascular risk in the setting of HIV infection remain unclear. Accelerated vascular disease could be a common pathway linking CKD and CVD given their shared risk factors and the adverse effects of reduced kidney function on blood pressure control, inflammation, insulin resistance, and dyslipidemia. We hypothesized that albuminuria and reduced kidney function would be associated with subclinical vascular disease in HIV-infected individuals. To this end, we determined the association of $\mathrm{eGFR}_{\mathrm{Cys}}$, creatinine-based eGFR $\left(e G F R_{C r}\right)$, and prevalence of albuminuria with cIMT as measured in the second examination of FRAM.

\section{Methods}

\section{Study Participants and Design}

FRAM was originally designed to evaluate the association of HIV infection and its treatment with changes in body composition and metabolic abnormalities. The methods of FRAM have previously been described in detail [12]. Between June 2000 and September 2002, 1,183 HIV-infected individuals were recruited from 16 geographically diverse HIV or infectious disease clinics. The demographics of the FRAM cohort were similar to those of a national random sampling of HIV-infected individuals in the United States [12]. Exclusion criteria for FRAM included: age less than 18 years, pregnancy or plan for pregnancy within 3 months of enrollment, and contraindication to magnetic resonance imaging or dual-energy $\mathrm{x}$-ray absorptiometry scanning. Between October 2004 and August 2007, a second examination was conducted which included ultrasonographic assessment of cIMT. The current cross-sectional study used data collected at this 5-year follow-up visit of FRAM. FRAM year 5 retention outcomes for participants initially enrolled have been reported [13]. Of the 581 HIV-infected participants examined at this visit, we restricted our analysis to the 476 participants who had IMT measurements available and were free of self-reported clinical CVD at the time of the ultrasound scan [3]. Institutional review board approval was obtained at each participating center, and informed consent was obtained from all participants.

\section{Predictors}

Cystatin C was measured by a BNII nephelometer (Siemens, Inc., Deerfield, Ill., USA) that used a particle-enhanced immunonephelometric assay ( $\mathrm{N}$ Latex Cystatin $\mathrm{C}$ ) in serum specimens previously frozen and stored at $-70^{\circ} \mathrm{C}$ [14]. The coefficient of variation for between-run precision was less than $2 \%$ for cystatin $\mathrm{C}$ [14]. eGFR $\mathrm{Cys}_{\text {s }}$ was estimated from serum cystatin C levels using the CKD Epidemiology Collaboration equation $\left(\mathrm{eGFR}_{\mathrm{Cys}}=76.7\right.$ $\times$ cysC $^{-1.19}$ ) [15]. eGFR Cys $_{\text {was capped at }} 120 \mathrm{ml} / \mathrm{min} / 1.73 \mathrm{~m}^{2}$, as higher estimates are unlikely to be accurate or precise. Creatinine level was measured by the enzymatic method at Covance Laboratories (Indianapolis, Ind., USA); $\mathrm{GFFR}_{\mathrm{Cr}}$ was calculated using the abbreviated (4-variable) Modification of Diet in Renal Disease (MDRD) equation [16], as in prior FRAM studies, and also capped at $120 \mathrm{ml} / \mathrm{min} / 1.73 \mathrm{~m}^{2}$. A random urine sample was used to assess for albuminuria. Albuminuria was defined as the presence of a positive result on a urine dipstick $(\geq 1+)$, or the presence of a spot albumin-to-creatinine ratio $>30 \mathrm{mg} / \mathrm{g}$ on laboratory examination.

\section{Covariates}

Age, sex, race, personal and family medical history, smoking history, current medication use, and drug use were assessed by standardized questionnaires [12]. Height, weight and blood pressure were measured by standardized protocols. Hypertension was defined as a systolic blood pressure $>140 \mathrm{~mm} \mathrm{Hg}$, a diastolic blood pressure $>90 \mathrm{~mm} \mathrm{Hg}$, or antihypertensive medication use. Diabetes was defined as a fasting blood glucose level of $126 \mathrm{mg} / \mathrm{dl}$ or higher or reported use of insulin or oral hypoglycemic medication. All laboratory measurements of lipid levels, glucose metabolism and other markers from blood specimens were performed at Covance Laboratories. Total and regional subcutaneous adipose tissue (SAT), visceral adipose tissue (VAT), and lean body mass 




Fig. 1. Mean common cIMT by quartile of eGFR $\mathrm{Cyy}_{\text {. }}$. Bars represent $95 \%$ confidence intervals. IMT levels were calculated for each eGFR quartile using LS-means from a linear GEE regression model with the dependent variable cIMT. Common cIMT model adjusts for age, gender, race, antihypertensive use, systolic blood pressure, diastolic blood pressure, current smoking, skeletal muscle, CD4 lymphocyte count, and tenofovir duration. ${ }^{*} \mathrm{p}<0.05$ compared with quartile 4 .

were measured by magnetic resonance imaging as described previously [12]. HIV-related covariates included CD4 lymphocyte count, HIV RNA levels, duration of antiretroviral use (self-reported and on the basis of abstracted medication information at the HIV clinic sites) and duration of HIV infection (defined as time since first positive HIV diagnosis). Hepatitis $\mathrm{C}$ virus (HCV) RNA levels were measured using the Bayer Versant 3.0 (bDNA) assay (Bayer Diagnostics, Berkeley, Calif., USA); values $\geq 615$ IU/ $\mathrm{ml}$ were defined as $\mathrm{HCV}$-positive.

\section{Outcomes}

High-resolution B-mode ultrasonography was performed to capture images of the right and left, near and far walls of the common carotid and internal carotid arteries [17]. The assessment of cIMT in FRAM has been described previously [3]. Ultrasound images were analyzed centrally at the Ultrasound Reading Center (Department of Radiology, Tufts Medical Center, Boston, Mass., USA) to calculate the maximum near-wall and far-wall cIMT at each arterial site. The maximal cIMT of the common carotid artery was calculated as the mean of the maximum cIMT of the near and far walls of the right and left sides. Maximal wall thickness of the internal carotid artery was computed by the same method but also included measurements of the bulb region. A subset of patients $(n=77)$ had replicate readings, the same ultrasound scan read by two different readers. As in previous analyses [3], we included these replicates in our analysis using generalized estimating equations (GEEs), adjusting for IMT reader to account for the repeated measures.

Kidney Function and cIMT in HIV Infection

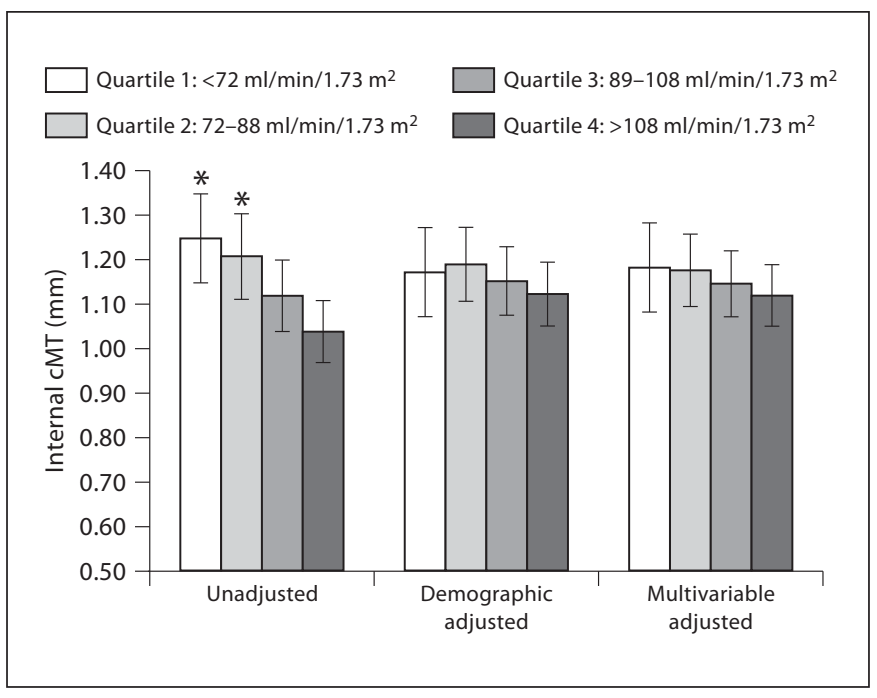

Fig. 2. Mean internal cIMT by quartile of eGFR $\mathrm{C}_{\text {Cys. }}$. Bars represent 95\% confidence intervals. IMT levels were calculated for each eGFR quartile using LS-means from a linear GEE regression model with the dependent variable cIMT. Internal cIMT model adjusts for age, gender, race, antihypertensive use, hypolipidemic use, HDL, current smoking, HIV RNA, and indinavir duration. ${ }^{*} \mathrm{p}<0.05$ compared with quartile 4 .

\section{Statistical Analysis}

We compared demographic and clinical characteristics across quartiles of GFFR $_{\text {Cys }}$, using Fisher's exact test for categorical variables, and the Kruskal-Wallis test for continuous variables, because many measures were non-normally distributed. To account for replicate cIMT readings in a subset of participants $(n=77)$ as noted above, we used linear GEEs with robust standard errors [18] to evaluate the association of eGFR $\mathrm{Cys}_{\mathrm{s}}, \mathrm{eGFR}_{\mathrm{Cr}}$, and albuminuria with common and internal/bulb cIMT. The semi-parametric GEE method is useful for correlated data when the normality assumption may not be valid. All analyses were adjusted for IMT reader. Multiple imputation was performed for missing covariates using the Markov chain Monte Carlo method for arbitrary missing data [19]. We evaluated the associations between predictor and outcome variables in stages: unadjusted analysis; adjusted for demographic characteristics (age, sex and race); and, multivariate-adjusted analyses incorporating demographics and selected CVD risk factors and HIV-related covariates that were associated with $\mathrm{eGFR}_{\mathrm{Cys}}$. The final multivariate-adjusted models were built separately for each outcome (common and internal cIMT) using a stepwise regression with a p value of 0.05 or less for entry and retention of covariates. We also conducted a sensitivity analysis to account for those with missing cIMT, adjusting estimates using an inverse probability weighting approach by modeling the participant's probability of having non-missing cIMT [20]. The inverse of this probability was then used as a weight applied to persons with nonmissing cIMT in the linear GEE regression analysis of cIMT.

IMT levels in figures 1 and 2 were calculated for each eGFR quartile using least-squares means (LS-means) from a linear GEE 
Table 1. Demographic and clinical characteristics of participants by quartile of eGFR $\mathrm{C}_{\mathrm{c}}$

\begin{tabular}{|c|c|c|c|c|c|}
\hline & \multicolumn{4}{|c|}{ Quartile of eGFR ${ }_{\text {Cys }}$} & \multirow[t]{2}{*}{$\mathrm{p}$ value } \\
\hline & $\begin{array}{l}1 \\
(\mathrm{n}=117)\end{array}$ & $\begin{array}{l}2 \\
(\mathrm{n}=118)\end{array}$ & $\begin{array}{l}3 \\
(n=118)\end{array}$ & $\begin{array}{l}4 \\
(n=118)\end{array}$ & \\
\hline Range of $\mathrm{eGFR}_{\mathrm{Cys}}, \mathrm{ml} / \mathrm{min} / 1.73 \mathrm{~m}^{2}$ & $<71.8$ & $71.8-88.2$ & $88.3-107.5$ & $>107.5$ & \\
\hline Age, years & $50(46,55)$ & $48.5(42,54)$ & $46(42,51)$ & $45(39,50)$ & $<0.001$ \\
\hline Female & $32(27 \%)$ & $34(29 \%)$ & $30(25 \%)$ & $48(41 \%)$ & 0.05 \\
\hline \multicolumn{6}{|l|}{ Race } \\
\hline African-American & $49(42 \%)$ & $54(46 \%)$ & $46(39 \%)$ & $40(34 \%)$ & \multirow[t]{3}{*}{0.3} \\
\hline Caucasian & $55(47 \%)$ & $47(40 \%)$ & $61(52 \%)$ & $58(49 \%)$ & \\
\hline Other & $13(11 \%)$ & $17(14 \%)$ & $11(9 \%)$ & $20(17 \%)$ & \\
\hline \multicolumn{6}{|l|}{ Smoking Status } \\
\hline Current & $47(40 \%)$ & $52(44 \%)$ & $40(34 \%)$ & $24(21 \%)$ & \multirow[t]{3}{*}{0.007} \\
\hline Past & $26(22 \%)$ & $28(24 \%)$ & $26(22 \%)$ & $33(28 \%)$ & \\
\hline Never & $44(38 \%)$ & $38(32 \%)$ & $52(44 \%)$ & $60(51 \%)$ & \\
\hline Total cholesterol, mg/dl & $179(150,215)$ & $183(154,214)$ & $180(155,217)$ & $187(162,215)$ & 0.7 \\
\hline High-density lipoprotein, mg/dl & $39(32,52)$ & $41(33,54)$ & $43(37,54)$ & $47(39,59)$ & $<0.001$ \\
\hline Diabetic & $10(9 \%)$ & $16(14 \%)$ & $7(6 \%)$ & $5(4 \%)$ & 0.06 \\
\hline Fasting glucose, mg/dl & $92(84,104)$ & $95(85,101)$ & $94(85,100)$ & $93(86,100)$ & 0.9 \\
\hline Insulin, $\mu \mathrm{U} / \mathrm{ml}$ & $17(11,27)$ & $16(10,27)$ & $14(10,20)$ & $14(10,20)$ & 0.03 \\
\hline Systolic blood pressure, $\mathrm{mm} \mathrm{Hg}$ & $123(114,135)$ & $128(116,140)$ & $119(113,134)$ & $121(113,129)$ & 0.03 \\
\hline Diastolic blood pressure, $\mathrm{mm} \mathrm{Hg}$ & $78(70,86)$ & $79(73,84)$ & $77(71,84)$ & $76(70,83)$ & 0.3 \\
\hline \multicolumn{6}{|l|}{ Family history of MI } \\
\hline Father & $25(22 \%)$ & $26(22 \%)$ & $18(16 \%)$ & $19(17 \%)$ & 0.8 \\
\hline Mother & $21(19 \%)$ & $17(15 \%)$ & $13(12 \%)$ & $16(14 \%)$ & 0.6 \\
\hline Body mass index & $25(22,27)$ & $25(22,29)$ & $25(22,28)$ & $25(23,28)$ & 0.8 \\
\hline Lipid-lowering medication & $19(16 \%)$ & $31(27 \%)$ & $30(26 \%)$ & $29(25 \%)$ & 0.2 \\
\hline Antihypertensive medication & $36(31 \%)$ & $34(29 \%)$ & $31(27 \%)$ & $23(20 \%)$ & 0.3 \\
\hline ACE use & $16(14 \%)$ & $17(15 \%)$ & $12(10 \%)$ & $10(8.7 \%)$ & 0.5 \\
\hline ARB use & $2(1.7 \%)$ & $2(1.7 \%)$ & $2(1.7 \%)$ & $3(2.6 \%)$ & 0.9 \\
\hline ART & $109(93 \%)$ & $112(95 \%)$ & $110(94 \%)$ & $112(96 \%)$ & 0.8 \\
\hline CD4 lymphocyte count & $356(198,526)$ & $372(240,622)$ & $441(339,599)$ & $463(336,656)$ & 0.001 \\
\hline Detectable HIV RNA & $47(41 \%)$ & $37(32 \%)$ & $29(25 \%)$ & $19(17 \%)$ & $<0.001$ \\
\hline \multicolumn{6}{|l|}{ HIV RNA, copies/ml } \\
\hline Below detectable & $68(59 \%)$ & $78(68 \%)$ & $88(75 \%)$ & $96(84 \%)$ & \multirow[t]{3}{*}{0.003} \\
\hline $400-10,000$ & $20(17 \%)$ & $12(10 \%)$ & $15(13 \%)$ & $10(8.7 \%)$ & \\
\hline$>10,000$ & $27(24 \%)$ & $25(22 \%)$ & $14(12 \%)$ & $9(7.8 \%)$ & \\
\hline HIV duration, years & $14(10,17)$ & $12(10,16)$ & $13(10,17)$ & $12(9,15)$ & 0.009 \\
\hline HCV RNA+ & $42(36 \%)$ & $28(24 \%)$ & $24(21 \%)$ & $12(10 \%)$ & $<0.001$ \\
\hline Heroin & $28(24 \%)$ & $26(22 \%)$ & $23(20 \%)$ & $18(15 \%)$ & 0.4 \\
\hline $\mathrm{eGFR}_{\mathrm{Cr}}, \mathrm{ml} / \mathrm{min} / 1.73 \mathrm{~m}^{2}$ & $78(62,96)$ & $90(76,109)$ & $97(86,113)$ & $108(95,120)$ & $<0.001$ \\
\hline Presence of albuminuria & $47(52 \%)$ & $28(35 \%)$ & $30(30 \%)$ & $20(21 \%)$ & $<0.001$ \\
\hline
\end{tabular}

Continuous variables are displayed as median (IQR). Dichotomous variables are displayed as number (\%).

$\mathrm{ACE}=$ Angiotensin-converting enzyme; $\mathrm{ARB}=$ angiotensin receptor blocker; eGFR = estimated glomerular filtration rate; $\mathrm{ART}=$ antiretroviral therapy; $\mathrm{HCV}=$ hepatitis $\mathrm{C}$ virus; $\mathrm{HIV}=$ human immunodeficiency virus; $\mathrm{IQR}=$ interquartile range; $\mathrm{MI}=$ myocardial infarction.

regression model with the dependent variable cIMT, adjusting for covariates included in table 2. LS-means are within-group means adjusted for other effects in the model and are also known as population marginal means [21]. All analyses were conducted using the SAS system, version 9.2 (SAS Institute, Inc., Cary, N.C., USA).

\section{Results}

The cIMT was measured in 476 HIV-infected individuals without clinical evidence of CVD. The demographics of the slightly smaller subset $(n=471)$ with cystatin C 
Table 2. Association of eGFR and albuminuria with cIMT in HIV-infected individuals

\begin{tabular}{|c|c|c|c|c|c|c|c|c|c|}
\hline & \multicolumn{3}{|c|}{ Unadjusted analysis } & \multicolumn{3}{|c|}{ Demographic-adjusted analysis ${ }^{1}$} & \multicolumn{3}{|c|}{ Multivariable-adjusted analysis ${ }^{2}$} \\
\hline & $\begin{array}{l}\text { Estimate } \\
\text { (per mm) }\end{array}$ & $95 \%$ CI & $\mathrm{p}$ value & $\begin{array}{l}\text { Estimate } \\
\text { (per mm) }\end{array}$ & $95 \%$ CI & $\mathrm{p}$ value & $\begin{array}{l}\text { Estimate } \\
\text { (per mm) }\end{array}$ & $95 \% \mathrm{CI}$ & $\mathrm{p}$ value \\
\hline \multicolumn{10}{|l|}{ Common cIMT } \\
\hline$e G R_{C y s}{ }^{3}$ & 0.008 & $0.003,0.013$ & 0.003 & -0.003 & $-0.007,0.002$ & 0.3 & -0.004 & $-0.008,0.001$ & 0.1 \\
\hline $\mathrm{eGFR}_{\mathrm{Cr}}{ }^{3}$ & 0.008 & $0.002,0.014$ & 0.01 & -0.002 & $-0.007,0.004$ & 0.5 & -0.003 & $-0.008,0.003$ & 0.3 \\
\hline Presence of albuminuria & 0.021 & $-0.007,0.049$ & 0.1 & -0.008 & $-0.036,0.019$ & 0.6 & -0.006 & $-0.042,0.030$ & 0.8 \\
\hline \multicolumn{10}{|l|}{ Internal cIMT } \\
\hline $\mathrm{eGFR}_{\mathrm{Cys}}{ }^{3}$ & 0.024 & $0.008,0.039$ & 0.003 & 0.000 & $-0.015,0.015$ & 0.9 & 0.003 & $-0.012,0.019$ & 0.7 \\
\hline $\mathrm{eGFR}_{\mathrm{Cr}}^{3}$ & 0.029 & $0.010,0.047$ & 0.003 & -0.003 & $-0.021,0.016$ & 0.8 & 0.001 & $-0.020,0.021$ & 0.9 \\
\hline Presence of albuminuria & 0.005 & $-0.087,0.097$ & 0.9 & -0.045 & $-0.137,0.047$ & 0.3 & -0.01 & $-0.107,0.086$ & 0.8 \\
\hline \multicolumn{10}{|c|}{ 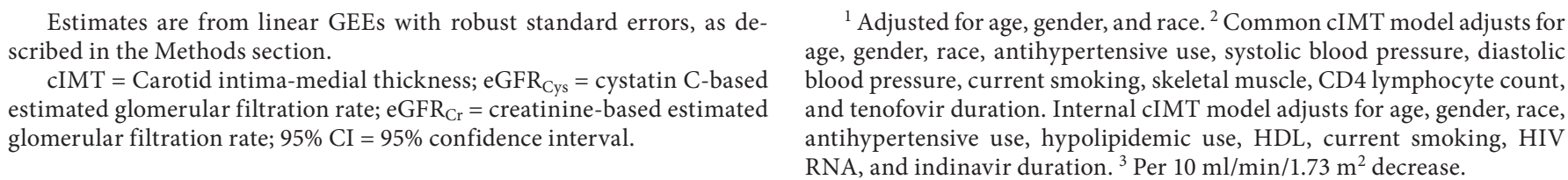 } \\
\hline
\end{tabular}

measurements are shown in table 1 . The mean age of the study participants was 48 years. Females comprised $31 \%$ of the study sample. The overall median values for $\mathrm{eGFR}_{\mathrm{Cys}}$ and $\mathrm{eGFR}$ Cr among study participants were 88 $\mathrm{ml} / \mathrm{min} / 1.73 \mathrm{~m}^{2}$ (interquartile range (IQR), 72,108 ) and $94 \mathrm{ml} / \mathrm{min} / 1.73 \mathrm{~m}^{2}$ (IQR, 79, 113), respectively. Of the 369 patients with urine albumin measured, the prevalence of albuminuria was $34 \%$.

Participants with lower eGFR $\mathrm{Cys}_{\mathrm{C}}$ were older and more often men compared to those with higher eGFR $\mathrm{Cys}_{\mathrm{s}}$. There were no statistically significant differences in race across quartiles of eGFR $\mathrm{Cys}_{\text {s }}$. Participants in the lower quartiles of $\mathrm{eGFR}_{\mathrm{Cys}}$ had higher prevalence of smoking, lower HDL levels, and higher systolic blood pressures. The prevalence of diabetes appeared higher in the lower quartiles of eGFR $\mathrm{Cys}_{\mathrm{s}}$, but did not reach statistical significance $(p=0.06)$. Insulin levels were modestly higher in patients with lower eGFR $\mathrm{Cys}_{\text {s }}$. There were no statistically significant differences in the use of lipid-lowering medications, angiotensin-converting enzyme inhibitors, or angiotensin receptor blockers across quartiles of eGFR $\mathrm{Cys}_{\mathrm{s}}$. As previously reported [8], patients with lower $\mathrm{GGFR}_{\mathrm{Cys}}$ had lower CD4 lymphocyte counts, higher prevalence of HIV viremia, longer duration of HIV infection, and higher rates of coinfection with HCV. As anticipated, lower eG$\mathrm{FR}_{\mathrm{Cys}}$ was strongly associated with lower $\mathrm{eGFR}_{\mathrm{Cr}}$ and higher prevalence of albuminuria.

Overall mean values of common and internal cIMT were $0.86 \pm 0.16$ and $1.15 \pm 0.49 \mathrm{~mm}$, respectively. In the unadjusted analysis (fig. 1), patients in the lower two quartiles of eGFR Cys $_{\text {s }}$ had a significantly higher common cIMT compared to patients in the highest eGFR $\mathrm{Cys}_{\mathrm{s}}$ quartile (mean common cIMT $0.88 \pm 0.15$ and $0.89 \pm$ $0.16 \mathrm{~mm}$, respectively, in quartiles 1 and 2 , compared to $0.83 \pm 0.16 \mathrm{~mm}$ in quartile $4, \mathrm{p}<0.05)$. However, this association was attenuated by demographic factors alone (age, gender, and race). Multivariate adjustment, which also included traditional CVD risk factors, HIVrelated factors, and body composition, had little further effect. Similarly (fig. 2), there was a strong unadjusted association between eGFR $\mathrm{Cys}_{\mathrm{s}}$ and internal cIMT (mean internal cIMT $1.25 \pm 0.56$ and $1.21 \pm 0.52 \mathrm{~mm}$, respectively, in quartiles 1 and 2, compared to $1.04 \pm 0.39 \mathrm{~mm}$ in quartile $4, \mathrm{p}<0.01$ ). This association was also attenuated after adjustment for demographic factors, and little association was present after full multivariate adjustment.

In table 2, we display the multivariable linear regression analyses comparing eGFR $\mathrm{Cys}_{\mathrm{s}}, \mathrm{eGFR}_{\mathrm{Cr}}$, and albuminuria with common and internal cIMT. Both eGFR $\mathrm{Cys}_{\mathrm{s}}$ and $e G R_{C r}$ were negatively associated with common and internal cIMT in the unadjusted analyses. However, the associations of eGFR $\mathrm{Cys}_{\mathrm{s}}$ and $\mathrm{eGFR}_{\mathrm{Cr}}$ with common and internal cIMT were largely attenuated after adjustment for demographic factors alone. The presence of albuminuria was associated with an increase in common cIMT of $0.021 \mathrm{~mm}$ in the unadjusted analysis, but the association did not reach statistical significance $(\mathrm{p}=0.14)$, and was completely attenuated after demographic adjustment. Albuminuria showed little association with internal cIMT. 
Results were similar in a sensitivity analysis that used inverse probability weighting to mitigate selection bias (supplemental table 1).

\section{Discussion}

In HIV-infected individuals without clinical evidence of CVD, reduced kidney function, as measured by cystatin $\mathrm{C}$ and creatinine, showed a statistically significant association with common and internal cIMT in unadjusted analyses. However, this association was accounted for entirely by demographic factors (age, gender, and race). Furthermore, there appeared to be minimal association between albuminuria and common or internal cIMT.

To our knowledge, this is the first study examining the relationship between reduced kidney function and subclinical vascular disease in the HIV-infected population. Contrary to our working hypothesis, our results suggest that accelerated atherosclerosis and vessel hypertrophy may not be the primary pathways by which kidney disease contributes to cardiovascular risk in HIV-infected patients. Interestingly, similar results were found in HIVuninfected populations. In the Multi-Ethnic Study of Atherosclerosis (MESA), a cohort of healthy individuals free of clinical CVD, Bui et al. [22] did not find an independent association between cystatin $\mathrm{C}$ and cIMT. Furthermore, in MESA, there was no independent association between cystatin $\mathrm{C}$ and measures of coronary calcification [23]. However, cystatin C was independently associated with a higher prevalence of left ventricular hypertrophy [24]. Similarly, albuminuria was independently associated with the presence of left ventricular hypertrophy, but was not associated with cIMT [25]. These findings suggest that kidney impairment in the general population may confer cardiovascular risk through mechanisms other than atherosclerosis, such as left ventricular remodeling, endothelial dysfunction, susceptibility to plaque rupture, hypercoagulability, or susceptibility to arrhythmia. Similar studies in the HIV-infected population would be of value to better understand the cardiovascular risk of HIV, as well as the contribution of kidney disease.

In the HIV population, few studies to date have examined the relationship between reduced kidney function and CVD. In a national sample of HIV-infected veterans, both albuminuria and $\mathrm{eGFR}_{\mathrm{Cr}}<60 \mathrm{ml} / \mathrm{min} / 1.73 \mathrm{~m}^{2}$ were associated with increased incidence of cardiovascular events [11]. From FRAM, a recent publication by Choi et al. [9] found that $\mathrm{eGFR}_{\mathrm{Cys}}$ and albuminuria were strong and independent risk factors for all-cause mortality. Unfortunately, the cause of death could not be determined in that study; therefore, it is unknown if these associations were present for cardiovascular-specific deaths. Nevertheless, these findings demonstrate the need to determine the underlying mechanisms by which kidney disease contributes to CVD and mortality in the setting of HIV infection. Although the increased risk of CVD does not appear to be mediated by accelerated atherosclerosis or vessel hypertrophy, as assessed by cIMT, further study is needed to investigate other potential pathways of disease.

There are several limitations to this study. First, its cross-sectional design allowed only one time point for data analysis. We are therefore unable to assess whether mild kidney disease might predict the progression of cIMT over a period of time. Second, of the 1,183 patients initially enrolled in FRAM, only 476 patients were present at the five-year follow-up visit, FRAM2, analyzed in this cross-sectional study. However, results were similar in a sensitivity analysis in which we used inverse probability weighting, suggesting that selection bias did not strongly impact our results. Third, although albuminuria data were available in only 369 of the 476 patients, we accounted for the missing data in our multivariate analyses using multiple imputation [19]. Fourth, in comparison with prior studies evaluating the relationship between kidney disease and CVD, our patient sample had relatively mild impairments in kidney function; the lowest quartile of eGFR $_{\text {Cys }}$ represented patients with an eGFR $<72 \mathrm{ml} /$ $\min / 1.73 \mathrm{~m}^{2}$. Given that the majority of our patients had relatively preserved kidney function, we cannot exclude the possibility that more severe kidney impairment might be independently associated with higher cIMT. Other limitations include our use of $\mathrm{eGFR}_{\mathrm{Cys}}$ and $\mathrm{GGFR}_{\mathrm{Cr}}$ rather than direct measurements of GFR, as well as our use of cIMT as a surrogate marker of subclinical vascular disease. Our chosen marker for preclinical atherosclerosis, cIMT, is a well-established measure of subclinical CVD, yet it is controversial whether increased cIMT represents true atherosclerosis or arterial wall hypertrophy.

In summary, we did not find an independent association between kidney disease and subclinical vascular disease in HIV-infected individuals. These results suggest that atherosclerosis and vessel hypertrophy may not be the primary pathways linking kidney disease to cardiovascular risk in HIV-infected individuals. Further studies are needed to elucidate the specific mechanisms by which kidney disease contributes to CVD and mortality in the setting of HIV infection. 


\section{Appendix}

Sites and Investigators: University Hospitals of Cleveland (Barbara Gripshover, MD); Tufts University (Abby Shevitz, MD (deceased) and Christine Wanke, MD); Stanford University (Andrew Zolopa, MD); University of Alabama at Birmingham (Michael Saag, MD); Johns Hopkins University (Joseph Cofrancesco, Jr., MD and Adrian Dobs, MD); University of Colorado Health Sciences Center (Lisa Kosmiski, MD and Constance Benson, MD); University of North Carolina at Chapel Hill (David Wohl, MD and Charles van der Horst, MD); University of California at San Diego (Daniel Lee, MD and W. Christopher Mathews, MD); Washington University (E. Turner Overton, MD and William Powderly, MD); VA Medical Center, Atlanta (David Rimland, MD); University of California at Los Angeles (Judith Currier, MD); VA Medical Center, New York (Michael Simberkoff, MD); VA Medical Center, Washington, D.C. (Cynthia Gibert, MD); St Luke's-Roosevelt Hospital Center, New York (Donald Kotler, MD and Ellen Engelson, $\mathrm{PhD}$ ); Kaiser Permanente, Oakland (Stephen Sidney, MD); University of Alabama at Birmingham (Cora E. Lewis, MD).

FRAM 2 Data Coordinating Center: University of Washington, Seattle (Richard A. Kronmal, PhD, Mary Louise Biggs, PhD, J.A. Christopher Delaney, PhD and John Pearce).

Image Reading Centers: St Luke's-Roosevelt Hospital Center, New York (Steven Heymsfield, MD, Jack Wang, MS and Mark Punyanitya) and Tufts New England Medical Center, Boston (Daniel H. O'Leary, MD, Joseph Polack, Anita P. Harrington).
Office of the Principal Investigator: University of California, San Francisco, Veterans Affairs Medical Center and the Northern California Institute for Research and Development: (Carl Grunfeld, MD, PhD, Phyllis Tien, MD, Peter Bacchetti, PhD, Michael Shlipak, MD, Rebecca Scherzer, PhD, Mae Pang, RN, MSN, Heather Southwell, MS, RD).

\section{Acknowledgements}

Funding Sources: Supported by NIH grants RO1-DK57508, HL74814, and HL53359, and NIH GCRC grants M01-RR00036, RR00051, RR00052, RR00054, RR00083, RR0636, RR00865, UL1 RR024131, and P30 DK 026687-269012, the Albert L. and Janet A. Schultz Supporting Foundation, and with resources and the use of facilities of the Veterans Affairs Medical Centers of Atlanta, District of Columbia, New York, and San Francisco.

Role of the Funder: The funder played no role in the conduct of the study, collection of the data, management of the study, analysis of data, interpretation of the data or preparation of the manuscript. Clinicaltrials.gov ID: NCT00331448.

\section{Disclosure Statement}

There are no conflicts of interest to declare.

\section{References}

1 Currier JS, Taylor A, Boyd F, Dezii CM, Kawabata H, Burtcel B, Maa JF, Hodder S: Coronary heart disease in $\mathrm{HIV}$-infected individuals. J Acquir Immune Defic Syndr 2003;33: 506-512.

-2 O’Leary DH, Polak JF, Kronmal RA, Manolio TA, Burke GL, Wolfson SK Jr: Carotidartery intima and media thickness as a risk factor for myocardial infarction and stroke in older adults. Cardiovascular Health Study Collaborative Research Group. N Engl J Med 1999;340:14-22.

3 Grunfeld C, Delaney JA, Wanke C, Currier JS, Scherzer R, Biggs ML, Tien PC, Shlipak MG, Sidney S, Polak JF, O’Leary D, Bacchetti P, Kronmal RA: Preclinical atherosclerosis due to HIV infection: carotid intima-medial thickness measurements from the FRAM study. AIDS 2009;23:1841-1849.

$\checkmark 4$ Humphreys MH: Human immunodeficiency virus-associated glomerulosclerosis. Kidney Int 1995;48:311-320.

5 Lucas GM, Eustace JA, Sozio S, Mentari EK, Appiah KA, Moore RD: Highly active antiretroviral therapy and the incidence of HIV1-associated nephropathy: a 12-year cohort study. AIDS 2004;18:541-546.
-6 Szczech LA, Grunfeld G, Scherzer R, Canchola JA, van der Horst C, Sidney S, Wohl D, Shlipak MG: Microalbuminuria in HIV infection. AIDS 2007;21:1003-1009.

7 Choi AI, Rodriguez RA, Bacchetti P, Bertenthal D, Volberding PA, O'Hare AM: The impact of HIV on chronic kidney disease outcomes. Kidney Int 2007;72:1380-1387.

-8 Odden MC, Scherzer R, Bacchetti P, Szczech LA, Sidney S, Grunfeld G, Shlipak MG: Cystatin $\mathrm{C}$ level as a marker of kidney function in human immunodeficiency virus infection: the FRAM study. Arch Intern Med 2007;167:2213-2219.

-9 Choi AI, Scherzer R, Bacchetti P, Tien PC, Saag MS, Gibert C, Szczech LA, Grunfeld C, Shlipak MG: Cystatin C, albuminuria, and 5-year all-cause mortality in HIV-infected persons. Am J Kidney Dis 2010;56:872-882.

10 Go AS, Chertow GM, Fan D, McCulloch CE, Hsu CY: Chronic kidney disease and the risks of death, cardiovascular events, and hospitalization. N Engl J Med 2004;351: 1296-1305.

11 Choi AI, Li Y, Deeks SG, Grunfeld C, Volberding PA, Shlipak MG: Association between kidney function and albuminuria with cardiovascular events in HIV-infected persons. Circulation 2010;121:651-658.
12 Tien PC, Benson C, Zolopa AR, Sidney S, Osmond D, Grunfeld C: The study of fat redistribution and metabolic change in HIV infection (FRAM): methods, design, and sample characteristics. Am J Epidemiol 2006; 163:860-869.

13 Cockerham L, Scherzer R, Zolopa A, Rimland D, Lewis CE, Bacchetti P, Grunfeld C, Shlipak M, Tien PC: Association of HIV infection, demographic and cardiovascular risk factors with all-cause mortality in the recent HAART era. J Acquir Immune Defic Syndr 2010;53:102-106.

$\checkmark 14$ Erlandsen EJ, Randers E, Kristensen JH: Evaluation of the Dade Behring N Latex Cystatin C Assay on the Dade Behring Nephelometer II System. Scand J Clin Lab Invest 1999;59:1-8.

15 Stevens LA, Coresh J, Schmid CH, et al: Estimating GFR using serum cystatin $\mathrm{C}$ alone and in combination with serum creatinine: a pooled analysis of 3,418 individuals with CKD. Am J Kidney Dis 2008;51:395-406.

16 Levey AS, Bosch JP, Lewis JB, Greene T, Rogers N, Roth D: A more accurate method to estimate glomerular filtration rate from serum creatinine: a new prediction equation. Modification of Diet in renal Disease Study Group. Ann Intern Med 1999;130:461-470. 
-17 O’Leary DH, Polak JF, Wolfson SK Jr, Bond MG, Bommer W, Sheth S, Psaty BM, Sharrett AR, Manolio TA: Use of sonography to evaluate carotid atherosclerosis in the elderly. The Cardiovascular Health Study. CHS Collaborative Research Group. Stroke 1991;22: 1155-1163.

- 18 Zeger SL, Liang KY: Longitudinal data analysis for discrete and continuous outcomes. Biometrics 1986;42:121-130.

$\checkmark 19$ Schafer JL: Multiple imputation: a primer. Stat Methods Med Res 1999;8:3-15.

20 Robins JM, Finkelstein DM: Correcting for noncompliance and dependent censoring in an AIDS Clinical Trial with inverse probability of censoring weighted (IPCW) logrank tests. Biometrics 2000;56:779-788.
21 Searle SR Speed FM, Milliken GA: Populations marginal means in the linear model: an alternative to least squares means. Am Statist 1980:216-221.

-22 Bui AL, Katz R, Kestenbaum B, de Boer IH, Fried LF, Polak JF, Wasserman BA, Sarnak MJ, Siscovick D, Shlipak MG: Cystatin C and carotid intima-media thickness in asymptomatic adults: The Multi-Ethnic Study of Atherosclerosis (MESA). Am J Kidney Dis 2009;53:389-398.

-23 Ix JH, Katz R, Kestenbaum B, Fried LF, Kramer H, Stehman-Breen C, Shlipak MG: Association of mild to moderate kidney dysfunction and coronary calcification. J Am Soc Nephrol 2008;19:579-585.
24 Moran A, Katz R, Jenny NS, Astor B, Bluemke DA, Lima JA, Siscovick D, Bertoni AG, Shlipak MG: Left ventricular hypertrophy in mild and moderate reduction in kidney function determined using cardiac magnetic resonance imaging and cystatin $\mathrm{C}$ : The Multi-Ethnic Study of Atherosclerosis (MESA). Am J Kidney Dis 2008;52:839848 .

25 Kramer $\mathrm{H}$, Jacobs DR Jr, Bild D, Post W, Saad MF, Detrano R, Tracy R, Cooper R, Liu K: Urine albumin excretion and subclinical cardiovascular disease. The Multi-Ethnic Study of Atherosclerosis. Hypertension 2005;46:38-43. 